\title{
RELASI IMAN DAN FIKIH
}

\author{
Muhammad Norhadi \\ IAIN Palangka Raya, Palangka Raya, Indonesia \\ Norhadi02202@gmail.com
}

Received:06-06-2019; Revised: 06-06-2019; Accepted: 06-06-2019

ABSTRACT

In its development Jurisprudence is a branch of science that very much touches aspects of the life of Muslims. It is even the most popular and important branch of Islamic science in Islam. But it turns out that the development of scientific theory in jurisprudence from time to time does not have a significant influence in practice in the field. In other words jurisprudence only develops in theoretical trajectories. While at the level of practice and reality there is no influence in the life of the Islamic community itself. So that there are so many fatwas and laws in jurisprudence that are considered to be the last wind by Muslims themselves. Therefore the author feels the need to conduct research and discussion on the causes of miss-praticing in the fiqh. This study uses normative-historical methods. The results of this study are that Jurisprudence at the beginning of its development is a branch of science that brings together all disciplines of both aqeedah, syariah, and muamalah. This includes the field of faith (faith). Then it can be said that Jurisprudence and Faith have very close and inseparable relationships. Each other ties together into a mutually moving unit. and submit to the laws of God which He has outlined.

Keywords: Fiqh, Iman, Relation

\section{INTISARI}

Dalam perkembangannya ilmu fikih merupakan cabang keilmuan yang sangat banyak menyentuh aspek kehidupan umat Islam. Bahkan merupakan cabang keilmuan Islam yang paling populer dan penting dalam Islam. Namun ternyata perkembangan teori keilmuan dalam fiqih dari masa-ke masa tidak begitu memberikan pengaruh yang signifikan dalam prakteknya dilapangan. Dengan kata lain fiqih hanya berkembang dalam lintasan teoritis. Sementara pada tataran praktek dan realita tidak memberikan pengaruh dalam kehidupan masyarakat Islam itu sendiri. Sehingga begitu banyak fatwa dan hukum dalam fiqih yang dianggap angin lalu oleh umat Islam sendiri. Oleh karena itu penulis merasa perlu untuk melakukan penelitian dan pembahasan mengenai penyebab terjadinya miss-praticing dalam fikih tersebut. Penelitian ini menggunakan metode normatif-historis. Hasil dari penlitian ini adalah bahwa fikih dalam awal perkembangannya adalah sebuah cabang ilmu yang menghimpun segala disiplin ilmu baik akidah, syariat, dan muamalah. Termasuk di dalamnya adalah bidang akidah (iman). Maka dapat dikatakan bahwa Fikih dan Iman memilki hubungan yang sangat erat tak terpisahkan. Satu sama lain saling mengikat menjadi suatu kesatuan yang saling menggerakan. dan tunduk kepada hukum-hukum Allah yang telah digariskan-Nya.

Kata Kunci: Fikih, Iman, dan Relasi 


\section{A. Pendahuluan}

Dalam perkembangannya ilmu fikih merupakan cabang keilmuan yang sangat banyak menyentuh aspek kehidupan umat Islam. Bahkan merupakan cabang keilmuan Islam yang paling populer dan penting dalam Islam. ${ }^{1}$ Namun ternyata perkembangan teori keilmuan dalam fiqih dari masa-ke masa tidak begitu memberikan pengaruh yang signifikan dalam prakteknya dilapangan. Dengan kata lain fiqih hanya berkembang dalam lintasan teoritis. Sementara pada tataran praktek dan realita tidak memberikan pengaruh dalam kehidupan masyarakat Islam itu sendiri. Sehingga begitu banyak fatwa dan hukum dalam fiqih yang dianggap angin lalu oleh umat Islam sendiri. ${ }^{2}$

Disamping itu, problem dan permasalahan fiqih juga terjadi pada kalangan intelektual muslim yang concern dalam bidang Syariat Islam. Hal ini dikarenakan adanya usaha dan gerakan yang berusaha meruntuhkan bangunan syariat Islam, yaitu beruasaha menggugat legalitas wahyu baik AL-Quran ${ }^{3}$ maupun Hadis. ${ }^{4}$ Dan Hal ini tentunya berefek langsung pada bangunan fikih yang memiliki peran sentral dalam syariat Islam sebagaimana dikemukakan di awal. Karena pada hakikatnya banguna fikih dibangun diatas landasan al-Quran dan Hadis. Pada Akhirnya hal ini akan menambah runyam persoalan fiqih dan prakteknya.

Berkaca pada hal di atas penulis merasa bahwa perkembangan pemikiran fikih yang "pesat" tidak begitu memberikan kontribusi pada perubahan dan kemajuan kehidupan umat. Dengan kata lain fikih hanya berkembang dalam tataran teoritis namun nihil dalam hal aplikasi praktis, padahal fokus fikih adalah amaliyah praktis. ${ }^{5}$ Oleh penulis ingin menyingkap tabir penyebab terjadinya miss-practicing terhadap ajara fikih yang telah begitu berkembang luar

\footnotetext{
${ }^{1}$ Begitu pentingnya fiqh ini, sampai ada yang mengatakan andaikan saja peradaban Islam bisa diungkapkan dengan salah satu produknya, maka kita akan menamakannya sebagai "Peradaban Fiqh", sebagaimana Yunani diidentikkan dengan "Peradaban Filsafat". Lihat Nirwan Syafrin, Konstruk Epistemologi Islam: Telaah bidang Figh dan Ushul Fiqh, Tsaqofah UNIDA Gontor, Vol 5, No 2 Dzul Qa'dah 2009, h. 228.

${ }^{2}$ Muhammad Muhtar Arifin Sholeh, Pola Penyimpangan Muslim Terhadap Ajaran Agamanya, al-Fikri, vol 1, Februari 2018, h

${ }^{3}$ Ide ini banyak disuarakan oleh Mohammad Arkoun, pemikir asal al-Jazair yang sudah puluhan tahun menetap di Perancis dan menjadi Professor di Sarbone University dalam bidang kajian keIslaman. Idenya ini dapat dibaca dalam beberapa karyanya seperti, Mohammad Arkoun, Al-Fikr al-Isla>mi: Qira>'ah 'Ilmiyyah (Beirut: Markaz al-Inma' al-Qawmi dan Al-Markaz al- Thaqafi al-'Arabi, 1996); idem, Al-Qur'an min al-Tafsir alMawru $>$ ts ila $>$ tahlil al-Khit ${ }^{2}>b$ al-Dini, terj. Hashim Saleh (Beirut: Dar al-Tali'ah li al-Tiba'ah wa al-Nasr); idem, Ta>rikhiyyah al-Fikr al- Islami, terj. Hashim Saleh (Beirut: Markaz al-Inma' al-Qawmi dan Al-Markaz alThaqafi al- 'Arabi,1996). Ringkasan ide-ide Arkoun tentang al-Qur'an ini dapat dibaca di Ahmad Idris al- Ta'an alHajj, "Intihak Qadasah al-Qur'an fi al-Khitab al-'Ilmani," Al-Muslim al-Mu'a>s\}̧ir, no. 115, 2005, p. 103 -123; Nu'man 'Abd al-Razzaq al-Samarra'i, Al-Fikr al-'Arabi wa al-Fikr al-Ishtishra> qi bayn Dr. Muhammad Arkoun wa Dr. Edward Sa'id (Riyad: Dar Tabari li al-Nashr wa al-Tawzi'), p. 57-66. Dan studi kritis atas idenya bisa dilihat pada, Abdul Kabir Hussain Solihu, Historicist Approach to the Qur'an: Impact of Nineteenth-century Western Hermeneutis in the Writings of Two Muslim Scholars: Fazlur Rahman dan Muhammad Arkoun (Kuala Lumpur, Disertasi Doktoral di International Islamic University Malaysia (IIUM), 2003), dan Adnin Armas, Metodologi Bibel dalam Studi al-Qur'an: Kajian Kritis (Jakarta: Gema Insani Press, 2005), p. 63-69.Nirwan Syafrin, Kritk terhadap Paham Liberalisasi Syariat Islam, Tsaqofah UNIDA Gontor, Vol 5, No 1 2009, h. 52; Lihat juga Irwan Malik Marpuang, Kritik Terhadap “Kritik Nalar Islam” Arkoun, Jurnal Islamia, Vol VI, No. 1 2012, h. 83-95.

${ }^{4}$ Husaen, Pinang, Hadis dalam Perspektif Jaringan Islam Liberal (Telaah Kritis Metodologi Penelitian dan Kualitas Hadis). Doktoral (S3) thesis, Universitas Islam Negeri Alauddin Makassar. 2014, h. Abstrak; lihat juga Ali Mustafa Yaqub, Kritik Hadis, Jakarta: Pustaka Firdaus, 2008, Cet. V, h. 109-123.

${ }^{5}$ Adian Husaini dkk, Filsafat Ilmu (Perspektif Barat dan Islam), Jakarta: Gema Insani, 2013, Cet. 10, h. 129.
} 
biasa tersebut. Adakah bagian penting yang terlewatkan dalam kajian fikih sehingga ada sesuatu yang hilang dan menyebabkan terjadinya ketimpangan dalam fikih. Dan ternyata dalam literatur fikih diterangkan bahwa istilah fikih yang dipakai oleh ulam pada masa kontemporer ini telah mengalami penyempitan makna. ${ }^{6}$ Ada komponen yang ditinggal dan dipisah dari bangunan awal fikih tersebut. Oleh karena itulah penulis merasa penting untuk dilakukan penilitian ini sehingga dapat diperoleh gambaran yang utuh dan jelas apa komponen yang ditinggal sehingga terjadinya ketimpangan dalam implementasi fikih dalam kehidupan umat Islam.

\section{B. Metode Penelitian}

Penelitian ini adalah kajian kepustakaan (library research) dengan metode deskriptif analitis. dengan menggunakan pendekatan normatif historis, data yang diambil dari data primer dan sekunder, dikaji kemudian dihimpun sehingga menjadi sebuah penelitian yang utuh.

\section{Hasil dan Pembahasan}

\section{Fikih dan Iman Dalam Terminologi Ulama}

a. Pengertian Fikih menurut Ulama

Al-Fiqh merupakan istilah bahasa arab yang berasal dari akar kata "faqiha-yafqahufaqhan", secara bahasa (etimologi) kata tersebut mengandung arti al-'Ilmu bi al-Syai wa alFahmu lahu wa al-Fathanatu" (pengetahuan, pemahaman, dan ketajaman pemikiran terhadap sesuatu). ${ }^{7}$ "Idrâk al-Syai' wa al-'Ilmu bihi" (mengetahui dan memahami sesuatu). ${ }^{8}$

Sedangkan ibnu Manzûr dalam kitabnya "Lisân al-Arab" menyatakan bahwa Al-Fiqh mengandung dua makna, pertama adalah, " الفطنة (kecerdasan atau ketajaman pemikiran) seperti dalam ungkapan;

$$
\text { خير الفقه ما ضرت به, وشر الرأي الدبري }
$$

Sebaik-baik pemahaman adalah yang dijaga dan seburuk-buruk pemikiran (al-Ra'yu) adalah yang menyimpang

$$
\text { وقال عيسى بن عمر : قال لي أعر ابي شهدت عليك بالفقه أي الفطنة. }
$$

'Isa bin Umar telah berkata, seorang berkebangsaan arab telah berkata kepadaku, saya bersaksi dihadapanmu dengan penuh kesadaran atau kecerdasan

Kedua adalah; "al-Fahm" (pemahaman) ${ }^{9}$, definisi kedua inilah yang menurut Ibnu Manzûr sebagai makna sebenarnya dari al-Fiqh, ${ }^{10}$ seperti yang terungkap dalam QS. al-Taubah: 122, yang berbunyi:

${ }^{6}$ Lihat, Ahmad Najihan Maududi, "Pemikiran Hukum Islam Ibnu Jarîr at-Thabarî̀" (tesis tidak diterbitkan, Program Pasca Sarjana Konsentrasi Syarî’ah UIN Syarif Hidayatullah, Jakarta 2007), h. 74.

${ }^{7}$ Thâhir Ahmad al-Zâdi, Tartîb al-Qâmûs al-Muhîth 'alâ Thariqah al-Mishbâh al-Munîr wa asas al-Balaghh, ( Riyadh: Dâr al-'illam al-Kutub, 1417 H/1996 M), Cet.,4, Juz.1, h. 513.

${ }^{8} \mathrm{Abu}$ al-Husein Ahmad bin Fâris bin Zakariya, Mu'jam Maqâyis al-Lughah, (Kairo: Maktabah al-Khanji, 1402 H/1981 M), Cet III, Vol. IV, h. 442.

${ }^{9}$ Dari pengertian yang ada, "al-Fiqh" lebih banyak diartikan oleh kebanyakan ahli kebahasaan sebagai "alFahm" bahkan tidak sedikit yang menyatakan bahwa " al-Fahm" adalah makna satu-satunya dari al-Fiqh tersebut, namun tidak dapat dipungkiri pada perkembangannya al-Fiqh secara terminologis telah mengalami perubahan makna. Pada perkembangannya, al-Fiqh yang semula diartikan menjadi "al- Fahm" kemudian dikatagorikan kedalam bagian dari ilmu, demikian itu telah mengundang perbedaan presepsi para ulama, terutama mengenai apakah "al-Fiqh" dalam arti "al-fahmu" dapat disamakan dengan al-Fiqh dalam arti "al- 'Ilmu"? 
Artinya; "Tidak sepatutnya bagi orang-orang yang mu'min itu pergi semuanya (ke medan perang). Mengapa tidak pergi dari tiap-tiap golongan di antara mereka beberapa orang untuk memperdalam pengetahuan mereka tentang agama dan untuk memberi peringatan. (atTaubah:122)

Kata-kata "tafaqqaha" dalam ayat dia atas digunakan untuk seorang yang diberikan pengetahuan agama atau dianugrahi pemahaman tentang agama, term itu juga kemudian dapat ditemukan dalam hadis Rasulullah SAW, dimana beliau pernah mendoakan Ibn Abbas agar dianugrahkan kepadanya pengetahuan yang mendalam tentang agama, beliau berdoa dengan ungkapan:

$$
\begin{aligned}
& \text { حدثنا عبد الله بن محمد قال حدثنا هاثم بن القاسم قال حدثنا ورقاء عن عبيد الله بن أبي يزيد عن بن عباس ثم أن أن النبي }
\end{aligned}
$$

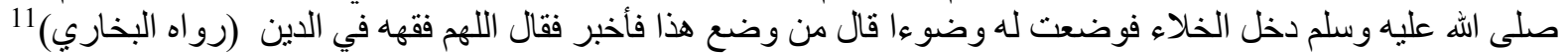

$$
\begin{aligned}
& \text { "...Ya Allah! Anugerahkan kepadanya pemahaman tentang agama" (HR. al-Bukharî) }
\end{aligned}
$$

Adapun pengertian fikih secara terminologi, para ulama menjelaskan maknanya dengan struktur bahasa yang berbeda, dan telah mengalami penyempitan makna. Berikut definisi yang dikemukakan oleh ulama:

\section{العلم بالاحكام الثر عية العملية المكتسب من أدلتها التفصيلية}

"Ilmu tentang seperangkat hukum-hukum syara' yang bersifat amaliah yang diperoleh dari dalil-dalil yang rinci (tafshiliyah). ${ }^{13}$

Dari uraian definisi di atas, baik secara etimologis maupun terminologis, dapat disimpulkan bahwa terminologi " al-Fikih" secara geneologis telah mengalami perubahan makna (sifting paradigm), dari pengertiannya yang umum (global) hingga menjadi sempit dan terbatas. Argumentasi perubahan makna tersebut dapat diperkuat oleh adanya penggunaan term fikih dalam ayat al-Quran maupun hadis Nabi Saw sebagaimana yang telah disebut di atas, maka secara umum ayat al-Quran dan hadis tersebut secara tidak langsung telah menunjukkan bahwa kata fikih telah familiar dikalangan masyarakat saat itu bahkan term itu sudah merupakan bahasa keseharian, akan tetapi pengertiannya dipergunakan dalam konteks pembicaraan soal-soal

Menyikapi permasalahan tersebut, para ulama berbeda interpretasi, pertama; pendapat yang menyatakan bahwa "al-Fiqih hanya dapat diartikan menjadi "al-Fahm" saja dan tidak dapat diartikan menjadi "al- "Ilmu", dikarenakan kedua kata tersebut mengandung perbedaan dari sisi makna.

Pendapat yang kedua adalah; "al-Fiqh" dapat diartikan menjadi "al-'Ilm", demikian itu disebabkan adanya kesamaan dan keterkaitan makna antara keduanya, sisi keterkaitan tersebut adalah, dimana "al-Fahm" merupakan faktor yang dapat merubah tingkat pengetahuan seseorang. "al-Fiqh" juga dapat diibaratkan dengan "al-'Ilm" karena fikih adalah semacam ilmu pengetahuan, dengan demikian "al-Fahm" dapat didifinisikan menjadi "pikiran yang baik dari segi kesiapannya menangkap segala sesuatu yang dituntut", selain itu dapat dikatakan bahwa al-'Âlim (berpengetahuan) sudah dipastikan memiliki pemahaman, sedangkan setiap orang yang faham belum bisa dikatakan 'Âlim (berpengetahuan). ${ }^{9}$ Lihat al-Amidi, al-Ihkâm fi Ushûl al- Ahkâm, (Bairut: Dâr al-Fikr, 1403 H/1983 M), Vol. 1, h. 19, lihat juga Musthafa sa'id al-Khin, Dirasat Thârikhiyah li al-Fikih wa Ushûlihi wa Ittijâhât allatî Dzaharat Fîhâ, (Damaskus: Syirkah al- Muttahidah li al-Tauzî', 1404 H/1984 M), Cet.,1, h. 8.

${ }^{10}$ Ibnu Manzûr, Lisân al-'Arab, Cet,1, Vol. 13, h.522-523, lihat juga al-Baidhâwi, Syarh al- Badhasyi, (Bairut: Dâr al-Kutub al-'Ilmiah, tth), juz.1, h.19.

${ }^{11}$ Al-Bukhâri, al-Jâmi'al-Shahîh al-Mukhtashar, (Beirut: Dâr Ibnu Katsir al-Yamâmah, 1407 H/ 1987 M), Cet III, Juz I, h. 66.

${ }^{12}$ Abu Zahrah, Ushûl a-Fiqh...., h. 6

${ }^{13}$ Pada pemaparan definisi fiqh secara terminology penulis hanya mengemukakan definisi yang diberikan oleh Prof. Abu Zahrah. Karena, definisi ini yang umum digunakan dalam literature dan pembelajaran fiqih. 
keagamaan secara umum. ${ }^{14}$ cakupan pengertiannya tidak hanya digunakan dalam arti hukum Islam saja seperti yang difahamai sekarang melainkan ia juga mencakup aspek-aspek lain dalam agama Islam, seperti halnya menyangkut aspek dogmatis, teologis, dan moralitas sekaligus.

Pada periode Islam pertama, Ilmu agama terbatas kepada al-Quran dan al- Sunnah saja, sedangkan fakîh menurut istilah orang arab adalah, "orang-orang yang memahami agama Allah dari sumbernya yaitu al-Quran dan al-Sunnah, sebagaimana yang dilukiskan dalam salah satu Hadis Rasulullah SAW, yang berbunyi;

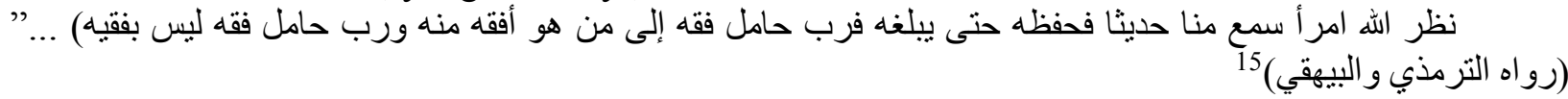

"Allah akan memperhatikan seseorang yang mendengarkan hadis dariku, ia menhafalkannya kemudian menyampaikannya kepada orang lain, maka berapa banyak ahli dalam fikih pergi berguru kepada orang yang lebih ahli darinya dan berapa banyak orang yang mengaku ahli dalam bidang fikih padahal sebenarnya tidak..." (HR. alTirmizi dan al-Baihaqi).

Kalimat fikih dalam hadis di atas diartikan menjadi "orang yang cerdas/bijaksana dalam masalah agamanya, yaitu orang yang dapat memahami makna nash sehingga dia mampu memahami hukum-hukum, petunjuk serta faedah-faedah yang terkandung dalam nash tersebut". ${ }^{16}$ Dengan adanya perputaran waktu dari masa ke masa, maka Pengertian fikih terus mengalami perubahan sejak periode Rasulullah, sahabat, al-Tâbi'în, Tabi'i al-Tâbi'în, hingga saat ini.

Pada Periode Rasulullah, fikih memimiliki makna sangat luas sebagaimana yang telah dijelaskan pada uraian di atas, definisi tersebut tidak mengalami perubahan sampai masa Tabi'în. Kitab "Fiqh al-Akbâr" baik yang dinisbahkan kepada Abu Hanifah maupun al-Syafi'i, dapat dijadikan bukti pelengkap akan keluasan arti fikih pada masa awal Islam baik secara teoritis maupun praktis, dengan argumentasi bahwa, kitab yang dikatakan sebagai fikih tersebut ternyata tidak hanya terbatas pada aspek dogmatis saja melainkan juga dapat ditemukan didalamnya aspek teologis dan moralitas, diantara pembahasan yang terdapat didalam karya tersebut adalah seperti; masalah keimanan, keesaan, dan sifat-sifat Allah, kehidupan akhirat, kerasulan, dan lain sebagainya. ${ }^{17}$

Berdasarkan uarain di atas dapat dipahami bahwa istilah fiqih sangat erat kaitannya dengan pemahaman yang mendalam meliputi Akidah (Iman), Ibadah, Muamalah dan AKhlak.

\footnotetext{
${ }^{14}$ Istilah fikih selain dapat ditemukan dalam ayat-ayat al-Quran juga dapat ditemukan dalam beberapa hadis باب السمر فى "' : Rasulullah Saw, bahkan al-Bukhari menjadikan term fikih sebagai bab khusus dalam shahihnya, yaitu diantara hadis tersebut adalah:

عن أبي هريرة رضي الله عنه أن رسول الله صلى الله عليه وسلم قال: الناس معادن، خياركم فى الجاهلية خيارهم في الإسلام إذا فقهوا (رواه الذاه

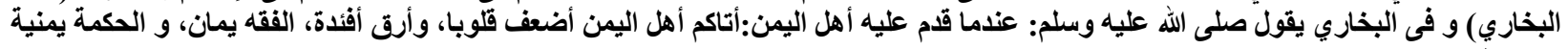
(رواه البخاري)

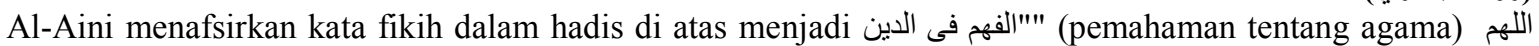
فقهه فى الدين ( رواه مسلم) Lihat Musthafa sa'id al-Khin, Dirâsat Târîkhiyyah ..., h. 9.

${ }^{15}$ Abu Bakar Ahmad bin al-Husaen al-Baihaqi, Syi'ab al-Iman, (Beirut: Dâr al-Kutub al- 'Ilmiyah, 1410 H), Cet I, Juz II, h. 274, lihat juga dalam hadis lain, Muhammad bin Isa Abu Isa al- Tirmizi, al-Jâmi'al-Shahîh al-Sunan al-Tirmizi, (Beirut: Dâr Ihyâ al-Turâts al-'Arabi, t.th), Juz V, h. 33.

${ }^{16}$ Ahmad Najihan Maududi, "Pemikiran Hukum Islam Ibnu Jarîr at-Thabarî" (tesis tidak diterbitkan, Program Pasca Sarjana Konsentrasi Syarî’ah UIN Syarif Hidayatullah, Jakarta 2007), h. 74.

${ }^{17}$ Majd al-Dîn Muhammad bin Bahâ al-Dîn, al-Qaul al-Mufasshal Syarh al-Fikih al-Akbar,(Istambul: Makabah al-Haqîqah, 1410 H/ 1990)
} 
Sehingga seorang faqih dalam generasi salaf adalah seorang yang memiliki iman yang mantap dan ilmu yang mendalam sehingga terwujud dalam pengamalan agamanya yang istiqomah. Sehingga ketika seorang belajar fiqih dia tidak hanya mengilmui pelbagai dalil. Namun juga mampu mengaplikasikannya dalam kehidupan pribadinya dan menjadi tauladan bagi umat.

\section{b. Pengertian Iman}

Iman adalah mashdar dari kata “aamana-yu'minu-iimaanan”. Secara etimologi kata iman bermakna al-tashdiq membenarkan”. Sedang mneurut Buya Hamka iman artinya parcaya. ${ }^{18}$ Percaya dalam Bahasa Indonesia artinya meyakini atau yakin akan sesuatu (yang dipercaya) itu memang benar aatau nyata adanya. ${ }^{19}$ Iman juga bermakna membenarkan dan mengakui (I'tiraf) pembenaran yang bersifat Khusus. ${ }^{20}$ Adapun menurut WJS. Poerwadarminta Iman adalah kepercayaan, Keyakina, Ketetapan hati atau keteguhan hati. ${ }^{21}$

Dari beberapa pengertian di atas dapat ditarik benang merah bahwa iman adalah percaya dan mengakui akan sesuatu yang diyakini tanpa ada keraguan.

Semetara secara terminologi para ulama memiliki pelbagai perbedaan dalam mendefinisikannya, namun saling melengkapi. yaitu diantaranya:

"Iman adalah perkataan dan amalan, bisa bertambah dan berkurang." (Diriwayatkan oleh anaknya 'Abdullah dalam kitab As Sunnah, 1: 207). ${ }^{22}$

Ibnu Taimiyah mendefinisikan Iman adalah: "Perkataan dan Perbuatan yang akan bertambah dengan ketaatan dan berkurang dengan kemaksiatan."

Imam Muhammad bin Isma'il bin Muhammad bin al Fadhl at Taimi al Asbahani mengatakan : "Iman menurut pandangan syariat adalah pembenaran hati, dan amalan anggota badan".

Imam Al Baghawi mengatakan : "Para sahabat, tabi' in, dan ulama ahlis sunnah sesudah mereka bahwa amal termasuk keimanan... mereka mengatakan bahwa iman adalah perkataan, amalan, dan aqidah"

Al Imam Asy Syafi'i berkata dalam kitab Al Umm : “ Telah terjadi ijma' (konsesus) di kalangan para sahabat, para tabi'in, dan pengikut sesudah mereka dari yang kami dapatkan bahwasanya iman adalah perkataan, amal, dan niat. Tidaklah cukup salah satu saja tanpa mencakup ketiga unsur yang lainnya"

Al Imam Al Laalikaa-i meriwayatkan dari Imam Bukhari : “ Aku telah bertemu lebih dari seribu ulama dari berbagai negeri. Tidak aku dapatkan satupun di antara mereka berselisih bahwasanya iman adalah ucapan dan perbuatan, bisa bertambah dan berkurang “ 23

Sedang menurut Imam Ibnu Qayyim mendefinisikan dengan panjang lebar iman adalah: Mengenal segala yang bersumber dari Rasulullah shallallahu alaihi wa sallam berdasarkan Ilmu, membenarkannya dengan Hati, diikrarkan dengan perkataan, tunduk patuh didasari rasa cinta, hadir dalam amal zhahir dan batin, dan mendakwahkannya sedaya upaya. ${ }^{24}$

\footnotetext{
${ }^{18}$ Hamka, Tasawuf Modern, Jakarta: Republika Penerbit, 2015, h. 62

${ }^{19}$ Kaelany HD, Iman, Ilmu dan AMal SHoleh, Jakarta: Rineka CIpta, 2000, h. 58.

${ }^{20}$ Abdul Rahman Abdul Khalid, Garis Pemisah antara kufur dan Iman, Jakarta: Bumi AKsara, 1996, h. 2.

${ }^{21}$ WJS Poerwadarminta, Kamus Umum Bahasa Indonesia, Jakarta: Balai Pustaka, 2000, h. 18.

${ }^{22}$ Muhammad Abduh Tausikal, https://rumaysho.com/5873-pengertian-iman-menurut-ahlus-sunnah.html, diakses pada 30 Mei 2019.

${ }^{23}$ Adika Mionaki,https://muslim.or.id/5478-iman-dalam-pandangan-ahlus-sunnah-wal-jamaah.html. diakses pada 30 Mei 2019.

${ }^{24}$ Ibnu Qayyim, al Fawaid, Bairut: Darul Nafais, 1986 M, Cet. VII, h.140.
} 
Berdasarkan definisi dari beberapa ulama diatas dapat disimpulkan bahwa mayoritas ulama ahlu sunnah menyatakan iman adalah pembenaran dengan Hati, diikuti oleh ikrar lisan, dan hadir dalam amal perbuatan, bertambah karena ketaatan dan berkurang karena kemaksiatan. Itulah haikat iman. Sehingga iman tidak cukup hanya diproklamirkan dengan lisan. Karena berapa banyak manusia yang menproklamirkan keimanannya. Namun ternyata mereka adalah musuh dalam selimut. Sebagaimana para munafik yang berikrar lantang atas iman namun hanya nyaring di lisan sepi sunyi di hati. Sebagaimana firman Allah yang artinya: "Di antara manusia ada yang mengatakan: "Kami beriman kepada Allah dan Hari kemudian," pada hal mereka itu sesungguhnya bukan orang-orang yang beriman. Mereka hendak menipu Allah dan orang-orang yang beriman, padahal mereka hanya menipu dirinya sendiri sedang mereka tidak sadar." (Al Baqarah: 8-9)

Iman juga bukan ceremony amal sholeh yang diperlihatkan dan dipertontonkan di khalayak Islam. Padahal tidaklah mereka beramal sholeh kecuali hanya mengharap selain Allah. Tidak ada keikhlasan dalam setiap amal mereka. Bahkan terkandung niat jahat di dalamnya. Sebagaimana firman Allah yang artinya: "Sesungguhnya orang-orang munafik itu menipu Allah, dan Allah akan membalas tipuan mereka. Dan apabila mereka berdiri untuk shalat mereka berdiri dengan malas. Mereka bermaksud riya (dengan shalat) di hadapan manusia. Dan tidaklah mereka menyebut Allah kecuali sedikit sekali.” (An-Nisa: 142).

Iman bukan semata-mata mengetahui arti dan hakikat iman, karena banyak orang yang mengetahui hakikat iman namun mereka tidak beriman. Sehingga pengetahuan mereka tidak mampu membuat mereka tergerak untuk mengamalkan pengetahuan mereka, bahkan mereka mengingkarinya. Sebagaimana firman Allah yang artinya: "Dan mereka mengingkarinya karena kezaliman dan kesombongan (mereka) padahal hati mereka meyakini (kebenaran)nya. Maka perhatikanlah betapa kesudahan orang-orang yang berbuat kebinasaan. " (an Naml: 14) ${ }^{25}$

Sehingga iman yang benar dan lurus adalah keimanan yang didasari ilmu dan keyakinan yang kuat didasari oleh ketundukan hati, kepatuhan, dan kerelaan dalam menjalankan perintah dengan hati yang ikhlas karena Allah.

\section{Relasi Iman dan Fikih}

Berdasarkan definisi iman yang telah dijelaskan di atas dapat dipahami bahwa amal sholeh adalah bagian dari iman. Keduanya memilki hubungan yang sangat kokoh syariah atau amal sholeh adalah manifestasi dari Iman/aqidah yang kokoh. Keduanya memiliki hubungan timbal balik.

\section{a. Iman adalah fondasi Amal Sholeh (Fikih)}

Iman adalah asas berlaku dan diterimanya amal sholeh. Amal sholeh tidak akan bernilai apa-apa tanpa dilandasi iman kepada Allah subhanahu wa ta'ala. Namun seorang mukmin yang tidak taat sementara di hatinya masih menyisakan setitik iman. Dia hanya akan dihukumi sebagai muslim yang fasik. Dan akan mendapatkan hukuman atas ketidaktaatannya tersebut. Sebaliknya orang yang melakukan kebaikan yang bermaca-macam namun tidak dilandasi iman kepada Allah subhanahu wa ta'ala, maka tidak akan berbuah pahala sedikit pun. Hal ini diterangkan oleh Allah dalam firman-Nya di dalam surah al kahfi ayat 103-105.

\footnotetext{
${ }^{25}$ Yusuf Qaradhawi, Iman dan Kehidupan, terj. Fachruddin HS, Jakarta: Bulan Bintang, 1983, Cet. 2, h. 25-
} 28. 


\section{b. Iman dan Fikih Saling Timbal Balik}

Iman adalah sebuah motor penggerak yang mampu menggerakan seorang muslim untuk taat dan tunduk kepada hokum-hukum Allah yang telah digariskan-Nya. Ketika iman melahirkan ketaatan dan ketundukan maka amal sholeh yang merupakan ketaatan itu pada gilirannya akan memperkuat kembali iman yang terhujam dalam dadanya. Sehingga, daya dorong iman unuk amal shaleh semakin kuat, dan amal shaleh mengalir semakin deras. ${ }^{26}$

Muhammad Syaltot mengatakan “ Akidah adalah fondasi. Diatasnya dibangun syariah. Syariah merupakan konsekuensi dari akidah. Ia memperkuat akidah. Tidak ada syariah dalam Islam kecuali bersama akidah, dan pengamalannya akan mantap dalam naungan akidah." Dalam prakteknya iman akan mendorong seorang muslim untuk menerapkan syariat-syariat Allah. Dan syariat yang hidup dalam amal seorang muslim akan memperkokoh keimanannya. Karena keimanan adalah kekuatan mental dan moral yang mengisyaratkan penghormatan terhadap syariah dan menjaga hukum-hukumnya. ${ }^{27}$ Berikut beberapa 'ibrah dan pelajaran betapa iman mampu menggerakan amal (fikih praktis). Berikut diantara buah manis iman yang terptari di hati para salafus sholeh:

\section{Kesadaran menunaikan kewajiban zakat}

Aset harta zakat yang ada di Indonesia sungguh luar biasa. ${ }^{28}$ Namun sebagaimana yang kita ketahui bahwa kesadaran umat muslim Indonesia untuk membayar zakat masih sangat rendah. Sehingga, penyerapan harta zakat masih sangat minim. Dan belum bisa menjadi sebab kesejahteraan bagi masyarakat muslim Indonesia. Padahal bangsa Indonesia adalah bangsa dengan masyarakat muslim mayoritas terbesar di dunia. Maka, ketika cahaya iman memenuhi hati sanubari. Maka tidak ada aral yang menghalangi seorang mukmin untuk menunaikan kewajibannya tersebut bahkan melebihkannya. sebagaimana yang terjadi pada zaman Rasulullah shallahhu 'alaihi wa sallam.

Ubay bin Ka'ab meriwayatkan bahwa dirinya diutus oleh Rasulullah shollallahu 'alaihi wa sallam untuk mengumpulkan harta zakat dari para mustahik. pada suatu hari dia mendatangi seorang mustahiq untuk mengambil zakat hartanya. Setelah seluruh harta zakatnya dikumpulkan berupa binatang ternak. Maka bagian zakat yang harus ditunaikan dari seluruh binatang ternaknya adalah unta muda (bintu Makhad). Setelah disampaikan kepada mustahiq bahwa zakat binatang ternaknya adalah seekor unta muda. Si mustahiq itu menjawab: "unta seperti ini tidak mampu menghasilkan susu dan bahkan tidak bisa dijadikan kendaraan untuk dikendarai". Maka mustahiq tersebut menyerahkan untuk muda yang lebih besar dan menghasilkan susu. Karena ia menganggap unta seperti itulah yang sesuai untuk dijadikan harta zakatnya. Namun Ubai bin Ka'ab menolaknya karena kadar zakat yang sesuai untuk harta zakatnya adalah seekor unta muda saja. Maka ubay pun membawanya kepada Rasulullah shollallahu alaihi wasallam untuk mendapatan persetujuan dari beliau. Ketika hal ini disampaikan kepada Rasulullah. Maka Rasulullah shollallahu alaihi wasallam menjelaskan bahwa kewajiban zakatnya adalah unta muda. Kemudian beliau menimpali apabila engkau menginginkan zakat dengan unta yang lebih

\footnotetext{
${ }^{26}$ Abas Mansur Taman, Islamic Worldview Paradigma intelektual muslim, Jakarta: Spirit Media, 2017, h. 3940.

${ }^{27} \mathrm{Ibid}, 40$

${ }^{28}$ Menurut data dari Pusat Kajian Strategis Baznas, potensi zakat secara nasional pada tahun 2011 mencapai 217 triliun rupiah, penelitian berikutnya pada tahun 2015 meningkat menjadi 286 triliun rupiah, dan terakhir pada tahun 2017 meningkat hampir seratus persen yakni 462 triliun rupiah. Lihat, Pusat Kajian Strategis Baznas, Outlook Zakat Indonesia 2018, Jakarta: Puskas Baznas, 2018, h. 3.
} 
baik, maka Allah akan mengganjarmu dengan pahala. Rasulullah shollallahu alaihi wasallam pun menerima zakatnya.

\section{Rela dirajam demi menaati Hukum}

Dalam peraturan perundang-undangan telah ditetapkan hukuman atas sesiapa saja yang melakukan tindak pelanggaran pidana. Hukuman ini ditetapkan agar menjadi efek jera bagi siapa saja yang melakukannya. Sehingga tidak akan mengulangi perbuatan tersebut. Namun pada realita yang ada banyak orang yang melakukan tindak pidana pelanggaran hukum. Bukannya malah taubat atau sadar akan keslahannya.mereka malah melakukan hal sebaliknya. Pelbagai cara dilakukan oleh para pelanggar hukum, agar terbebas dari jerat hukuman tersebut. Seperti ada yang lari melarikan diri dari daerah hukum tempatnya melakukan pelanggaran. Ada pula yang menyembunyikan kesalahannya dengan cara yang halusdan licin. Ada yang memanipulasi keslahannya seolah-olah tidak melanggar undang-undang yang berlaku. Atau berlindung kepada seorang penguasa yang bisa melindunginya.

Akan tetapi apabila kita memperhatikan bagaiman keimanan yang terhujam di dalam jiwa mampu membimbing empunya untuk mengakui keselahannya. Sehingga datang dengan sukarela kepada instansi yang berwenang dalam pelaksanaan hukum atas kesalahan yang dilakukan dengan harapan agar dosa-dosanya diampuni oleh Allah subhanahu wa ta'ala. Meskipun hukuman yang akan dia dapat dapat mencelakakan jiwanya. Diantara kisah iman tersebut adalah kisah salah seorang sahabat dusun bernama Ma'iz bin Malik dia datang menermui Rasulullah shollallahu alaihi wasallam. Mengadukan perbuatan yang telah dilakukannya. Berkata Mai'z kepada Rasulullah shollallahu alaihi wasallam: Ya Rasulullah saya telah menzholimi diri sendiri dengan berzina. Ssaya berharap agar engkau mau membersihkan dengan hukuman rajam. Namun Rasulullah shollallahu alaihi wasallam. Menjawabnya dengan lembut: Boleh jadi engkau hanya bersinggungan kulit dengannya,? Boleh jadi engkau hanya berciuman dengannya? Boleh jadi engkau hanya bertemu paha dengan paha?. Tetapi lelaki itu tetap bersikeras mengakui bahwa dirinya telah benar-benar berzina. Sehingga ia meminta agar dilaksanakan hukuman rajam atas dirinya. Dan itu dilakukannya semata-mata ikhlas karena Allah dan semata-mata menegakan hukum Allah. ${ }^{29}$

Kisah luar biasa berikutnya adalah kisah seorang wanita Arab Dusun yang bernama Ghamidiah. Dia datang melaporkan perbuatan zinanya yang telah menghasilkan janin di dalam kandungannya. Berkata ia kepada rasulullah : Ya rasulullah saya telah berzina, maka berikanlah hukum yang setimpal dengannya! Rasulullah menolak permintaan perempuan tadi. Maka pada besok hari perempuan itu datang lagi. Dan menyampaikan keberatannya kepada Rasulullah. Ia berkata: "mengapa engkau menolak permintaan saya ya rasulullah? Apakah karena engkau menolak perintaan Ma'iz. Maka ketahuilah sesungguhnya aku telah mengandung seorang anak dari hasil perzinahan tersebut. Maka rasulullah menjawab: " Silahkan pulang dan kembalilah ketika anakmu telah lahir."

Kemudian perempuan itu pulang sambil menunggu hari kelahiran anaknya. Namun walaupun hari terus berlalu hingga berganti bulan. Keinginannya untuk dihukum sesuai syariat atas kesalahannya tetaplah menyala di dadanya. Maka setalah anaknya lahir langsung ia membawanya kehadapan Rasulullah. Rasul pun langsung menjawab: " pualnglah dan susuilah anaknmu sampai dia berhenti menyusu". Ia pun pualng melaksanakan perintah rasulullah untuk menyusui anaknya hingga 2 tahun. Selama 24 bulan ia merawat dan menyusui buah hatinya

\footnotetext{
${ }^{29}$ Yusuf Qaradhawi, Iman dan Kehidupan....,h 193-194.
} 
dengan penuh kasih sayang. Sehingga tumbuh menjadi bayi yang lucu dan menggemaskan. Namu rentang waktu yang lama serta kelucuan buah hati tercinta, tidak sedikitpun memudarkan semangatnya untuk ditegakan syariat kepadanya atas kesalahan yang telah ia perbuat. ${ }^{30}$

\section{Iman mampu mengikis Budaya Penipuan, Curang, dan Korupsi}

Diriwayatkan pada masa khalifah Umar bin al khatab. Ketika khalifah Umar radhiallahu anhu mendapatkan laporan dan keluhan dari masyarakat bahwa ada sekelompok oknum penjual susu segar yang telah mencampur susu mereka dengan air demi mendapatkan keuntungan yang berlebih. Setelah mendengar dan menerima laporan ini. Khalifah umar segera mengeluarkan peraturan larangan atas susu segar oplosan. Walaupun peraturan ini telah diumumkan namun masih ada saja oknum yang melanggar peraturan ini. Karena itulah seorang penjual susu miskin ibu dan anak pun Karena siapa yang bisa menjamin dan selalu mengawasi para penjual susu agar tidak mencampur susu segarnya dengan air. Maka hanya bekal keimananlah yang mampu menjamin peraturan ini terlaksana sebagaimana mestinya. Maka terjadilah percakapan antara Ibu dan anak penjual susu di suatu malam gelap gulita. Yang tidak mereka sadari telah didengar oleh Amirul mukminin yang sedang melakukan kegiatan rutinnya mengitari kota madinah di malam hari. Maka sang ibu berkata: "Nak bagaimana kalau kita juga ikut mencampur susu segar kita ini dengan air? Agar mereka bisa mendapatkan untung lebih dari biasanya. Karena para penjual susu lain sudah melakukannya. Namun Si anak perempuannya menjawab: "Bukankah Amirul Mukminin telah melarang kita untuk mencampur Susu dengan air?. Si Ibu menimpali: “ dan Bukankah Amirul mukminin tidak melihat kita melakukannya. Si anak pun menjawab: “ memang benar wahai ibu amirul mukminin tidak melihat kita melakukan kecurangan ini, tapi Alla tuhannya Amirul mukminin Maha Melihat apa yang telah kita perbuat". ${ }^{31}$

Sungguh luar biasa sikap anak gadis beriman ini. Walaupun tidak ada yang mengetahui dan tidak ada kamera CCTV yang mengawasi atau pelbagai teknologi canggih yang mengawasi perbuatannya. Namun keimanannya kepada Allah telah mengantarkannya kepada ketaatan atas setiap perintah baik dalam ramainya manusia maupun kesendiriannya. Karena dia yakin bahwa Allah adalah zat yang Maha Tahu atas setiap perbuatannya.

\section{Keadilan seorang Hakim terhadap Yahudi dan Khalifah}

Diceritakan dalam suatu persiapan perang Baju besi Ali bin Abi Thalib hilang. Dan setelah beberapa waktu baju itu telah dipakai oleh seorang yahudi. Maka oleh iman Ali disapalah yahudi tersebut. Dan beliau menjelaskan bahwa baju zirah itu adalah milik beliau. Namun yahudi itu menolak dan menjawab bahwa baju itu miliknya karena dia yang memakainya sekarang. Khalifah Ali bin Abi thalib menimpali bahwa beliau sangat yakin bahwa baju besi itu adalah miliknya. Dan beliau mengajak yahudi itu untuk menyelesaikan perkara mereka di depan hakim. Yahudi itu pun menyetujui saran khalifah. Dan diputuskan bahwa hakimnya adalah Syuraih bin al Harits al Kindi hakim Kufah. Yahudi pun sempat meragukan keadilan hakim tersebut karena merasa dia adalah seorang yahudi dan Ali bin Abi Thalib adalah seorang khalifah. Maka khalifah ali meyakinkannya bahwa dia akan menjadi orang pertama yang akan meluruskan syuraih apabila dia berlaku tidak jujur. ${ }^{32}$

Kemudian mereka berdua mengahadap Syuraih. Kemudain Hakim Syuraih pun memberikan beberapa pertanyaan kepada kedua orang yang berperkara ini. Namun di tengah

\footnotetext{
${ }^{30}$ Ibid, h. 195 .

${ }^{31}$ Ali Muhammad Muhammad ash-Shalabi, Umar ibn Abdil Aziz Ma'alim at Tajdid wa al Ishlah al-Rasyid ala Minhaj an-Nubuwwah, Mesir: Dar Tawzi wa Nasyr al Islamiy, 2006, h. 13.

${ }^{32}$ Salim A Fillah, Lapis-lapis Keberkahan, Yogyakarta: Pro-U Media, 2014, h.493.
} 
proses introgasi itu khalifah Ali bin Abi Thalib menyela dan menegur Hakim Syuraih. Beliau menyampaikan bahwa ada sikap tidak adil yang telah dilakukan oleh syuraih kepada yahudi ini. Pertama adalah Hakim Syuraih memanggil Khalifah Ali dengan gelarnya sementara yahudi hanya nama. Kedua, hakim syuraih mendudukan khalifah di sampingnya sementara yahudi dihadapan mereka. Ketiga, hakim syuraih membiarkan jawaban khalifah Ali tanpa bantahan, sementara jawaban yahudi oleh hakim dicecar dengan pertanyaan balik. Setelah semua pertanyaan diajukan hakim syuraih menyimpulkan bahwa baju itu adalah baju besi milik khlifah yang jatuh dari kuda ketika di Auraq. Namun untuk memutuskan bahwa baju itu adalah milik khalifah hakim syuraih tetap harus memerlukan kesaksian dua orang lelaki adil. Kemudia khalifah mengajukan saksi Qanbur dan Hasan. Namun hakim syuraih menolak kesaksian Hasan karena dia adalah anak khalifah. Maka diputuskanlah bahwa baju besi itu adalah milik si yahudi. Karean khalifah ali tidak mampu menghadirkan dua orang saksi yang adil. Setelah menyaksikan keadilan kedua orang Mulia ini. Si yahudi pun langsung bersyahadat "Aku bersaksi bahwa barang itu adalah milik Anda wahai amirul mukminin. Ya Allah, amirul mukminin menghadapkan aku kepada seorang hakimnya, dan hakimnya memenangkan aku. Aku bersaksi bahwa agama yang mengajarkan seperti ini adalah agama yang benar dan suci. Aku bersaksi bahwa tiada ilah yang haq kecuali Allah dan bahwa Muhammad adalah utusan Allah. Wahai qadhi, ketahuilah bahwa barang ini adalah milik amirul mukminin, waktu itu aku mengikuti pasukannya ketika menuju ke Shiffin. Pakaian ini jatuh dari onta, lalu aku mengambilnya."33

Sungguh luar biasa kekuatan iman dalam membentuk pribadi-pribadi mulia yang senantiasa menjunjung tinggi hukum Allah dimana pun, kapan pun, dengan siapa pun. Sehingga setiap orang akan merasakan keadilan hatta seorang Yahudi pun merasakannya. Alangkah indahnya seandainya cahaya iman merasuk dalam pada setiap dada penegak hukum yang ada di negeri ini. Mungkin tidak akan ada lagi kasus banding karena setiap yang berperkara akan ikhlas dan ridha dengan keadilan para Hakim. Dari sini kita belajar bahwa keadilan akan dapat ditegakan apabila pemahaman fikih yang mendalam didorong oleh kekuatan iman yang terhujam dalam di setiap sanubari umat Islam.

Dari pelbagai penjelasan diatas sungguh sangat jelas dan terang benderang bahwa fiqh Islam memiliki ikatan yang kokoh lagi kuat dengan keimanan kepada Allah, diikat dengan sempurna pada rukun-rukun aqidah Islam, lebih-lebih aqidah iman kepada hari kiamat. Yang demikian karena aqidah iman kepada Allah akan menjadikan seorang Muslim berpegang teguh dengan hukum-hukum agama dan tunduk untuk menerapkannya secara sukarela dan berdasarkan kemauan sendiri. Karena barang siapa yang tidak beriman pada Allah Ta'alaa tidak akan terikat dengan sholat dan tidak dengan puasa dan juga tidak memperhatikan dalam berbagai aktivitasnya perkara halal maupun haram. maka terikat dengan hukum-hukum syariah sesungguhnya adalah cabang dari iman kepada Allah yang menurunkan hukum-hukum itu dan mensyariatkan hukumhukum itu untuk para hamba-Nya. ${ }^{34}$

\section{Kesimpulan}

Fikih adalah bidang ilmu yang paling penting dalam Islam. Karena ia meliputi hampir seluruh amalan praktis dala ajaran syariat Islam. Namun dalam sejarah awal perkembangannya ternyata fikih

\footnotetext{
${ }^{33}$ Abdurrahman Rafa'at Basya, Shuwar min Hayati Tabi'in, Yaman: Darul Adab Islami, 1997M, h. 114-117.

${ }^{34}$ Mushtafa Al-Khin dkk, Al Fiqh Al Manhajiy Ala Madzhabil Imam Asy Syafii, (Damaskus: Darul Qalam 1992), Juz. 1, h. 9
} 
tidak hanya terbatas pada amalan praktis un sich, tetapi fikih pada mula perkembangannya meliputi seluruh ajaran syariat, yaitu Akidah (Iman), Ibadah, Muamalah dan AKhlak. Sehingga seorang faqih dalam generasi salaf adalah seorang yang memiliki iman yang mantap dan ilmu yang mendalam sehingga terwujud dalam pengamalan agamanya yang istiqomah. Sehingga ketika seorang belajar fiqih dia tidak hanya mengilmui pelbagai dalil. Namun juga mampu mengaplikasikannya dalam kehidupan pribadinya dan menjadi tauladan bagi umat.

Adapun iman menurut ulama adalah pembenaran dengan Hati, diikuti oleh ikrar lisan, dan hadir dalam amal perbuatan, bertambah karena ketaatan dan berkurang karena kemaksiatan. Sehingga iman tidak semata amaliyah zhahir semata laksana topeng ketaatan namun kosong tanpa makna di hati. Atau pemahan teoritis namun sunyi dari implementasi real dalam kehidupan. Karena iman yang sejati adalah ilmu dan keyakinan yang kuat didasari oleh ketundukan hati, kepatuhan, dan kerelaan dalam menjalankan perintah dengan hati yang ikhlas karena Allah.

Maka dapat dikatakan bahwa Fikih dan Iman memilki hubungan yang sangat erat tak terpisahkan. Satu sama lain saling mengikat menjadi suatu kesatuan yang saling menggerakan. dan tunduk kepada hokum-hukum Allah yang telah digariskan-Nya. Ketika iman melahirkan ketaatan dan ketundukan maka amal sholeh yang merupakan ketaatan itu pada gilirannya akan memperkuat kembali iman yang terhujam dalam dadanya. Sehingga, daya dorong iman unuk amal shaleh semakin kuat, dan amal shaleh mengalir semakin deras. Dan pada akhirnya fikih wujud dalam setiap sendi kehidupan masyarakat dan membawa kepada islam rahmatan lil 'alamin karena fikih tidak hanya wujud dalam kitab, buku, dan ruang diskusi semata namun benar-benar hadir dalam kehidupan umat islam dan membawa keberkahan hidup bagi umatnya.

\section{DAFTAR PUSTAKA}

\section{A. Buku}

A Fillah, Salim, 2014, Lapis-lapis Keberkahan, Yogyakarta: Pro-U Media.

Abu al-Husein Ahmad bin Fâris bin Zakariya, 1402 H/1981 M, Mu’jam Maqâyis al-Lughah, Kairo: Maktabah al-Khanji, Cet III, Vol. IV.

al- Tirmizi, Muhammad bin Isa Abu Isa al-Jâmi'al-Shahîh al-Sunan al-Tirmizi, (Beirut: Dâr Ihyâ al-Turâts al-‘Arabi, t.th), Juz V.

al-'Asyqar, Umar Sulaiman, 2004, Siapakah Tuhammu?, (terjemahan), Jakarta: SAHARA Publishers,.

al-Amidi, 1403 H/1983 M, al-Ihkâm fi Ushûl al-Ahkâm, Bairut: Dâr al-Fikr, Vol. 1.

al-Baidhâwi, Syarh al-Badhasyi, Bairut: Dâr al-Kutub al-'Ilmiah, tth, Juz.1.

al-Baihaqi, Abu Bakar Ahmad bin al-Husaen, 1410 H, Syi ab al-Iman, Beirut: Dâr al-Kutub al'Ilmiyah, , Cet I, Juz II. 
Al-Bukhâri, 1407 H/ 1987 M, al-Jâmi'al-Shahîh al-Mukhtashar, Beirut: Dâr Ibnu Katsir alYamâmah, , Cet III, Juz I.

al-Dîn, Majd al-Dîn Muhammad bin Bahâ, , 1410 H/ 1990, al-Qaul al-Mufasshal Syarh al-Fikih al-Akbar, Istambul: Makabah al-Haqîqah.

al-Khin, Musthafa sa'id, 1404 H/1984 M Dirasat Thârikhiyah li al-Fikih wa Ushûlihi wa Ittijâhât allatî Dzaharat Fîhâ, Damaskus: Syirkah al- Muttahidah li al-Tauzî', Cet.,1.

Al-Qaradhawi,Yusuf, , 1979, Iman wa al-Hayah, Bairut: Muassasah ar-Risalah.

al-Zâdi,Thâhir Ahmad Tartîb al-Qâmûs al-Muhîth 'alâ Thariqah al-Mishbâh al-Munîr wa asas al-Balaghh, ( Riyadh: Dâr al-'illam al-Kutub, 1417 H/1996 M), Cet.,4, Juz.1.

Armas,, Adnin, , 2005, Metodologi Bibel dalam Studi al-Qur'an: Kajian Kritis Jakarta: Gema Insani Press.

ash-Shalabi, Ali Muhammad Muhammad Umar ibn Abdil Aziz, , 2006, Ma'alim at Tajdid wa al Ishlah al-Rasyid ala Minhaj an-Nubuwwah, Mesir: Dar Tawzi wa Nasyr al Islamiy.

Basya, Abdurrahman Rafa'at, , 1997, Shuwar min Hayati Tabi'in, Yaman: Darul Adab Islami.

Hamka, 2015, Tasawuf Modern, Jakarta: Republika Penerbit,

HD, Kaelany, 2000, Iman, Ilmu Dan Amal Sholeh, Jakarta: Rineka CIpta,

Husaini, Adian dkk, 2013 Filsafat Ilmu (Perspektif Barat dan Islam), Jakarta: Gema Insani, Cet. 10.

Ibnu Qayyim, al Fawaid, Bairut: Darul Nafais, 1986 M, Cet. VII.

Khalid, Abdul Rahman Abdul, 1996, Garis Pemisah antara kufur dan Iman, Jakarta: Bumi Aksara.

Manzûr, Ibnu, Lisân al-'Arab, Cet,1, Vol. 13.

Poerwadarminta, WJS, , 2000, Kamus Umum Bahasa Indonesia, Jakarta: Balai Pustaka

Pusat Kajian Strategis Baznas, , 2018, Outlook Zakat Indonesia 2018, Jakarta: Puskas Baznas.

Taman, Abas Mansur, 2017, Islamic Worldview Paradigma Intelektual Muslim, Jakarta: Spirit Media,

Yaqub, Ali Mustafa, 2008, Kritik Hadis, Jakarta: Pustaka Firdaus, Cet. V.

Yusuf Qaradhawi, 1983, Iman dan Kehidupan, terj. Fachruddin HS, Jakarta: Bulan Bintang.

B. Disertasi 
Pinang, Husaen, 2014, Hadis dalam Perspektif Jaringan Islam Liberal (Telaah Kritis Metodologi Penelitian dan Kualitas Hadis). Doktoral (S3) thesis, Universitas Islam Negeri Alauddin Makassar..

Maududi, Ahmad Najihan 2007, "Pemikiran Hukum Islam Ibnu Jarîr at-Thabarî̀" tesis tidak diterbitkan, Program Pasca Sarjana Konsentrasi Syarî’ah UIN Syarif Hidayatullah, Jakarta

\section{Jurnal}

Syafrin, Nirwan, 2009, Kritk terhadap Paham Liberalisasi Syariat Islam, Tsaqofah UNIDA Gontor, Vol 5, No 1.

2009, Konstruk Epistemologi Islam: Telaah bidang Fiqh dan Ushul Fiqh, Tsaqofah UNIDA Gontor, Vol 5, No 2 Dzul Qa'dah.

Sholeh, Muhammad Muhtar Arifin, 2018. Pola Penyimpangan Muslim Terhadap Ajaran Agamanya, al-Fikri, vol 1, Februari

Marpuang, Irwan Malik, Kritik Terhadap “Kritik Nalar Islam” Arkoun, Jurnal Islamia, Vol VI, No. 12012.

D. Internet

Muhammad Abduh Tausikal, https://rumaysho.com/5873-pengertian-iman-menurut-ahlussunnah.html, diakses pada 30 Mei 2019.

Adika Mionaki,https://muslim.or.id/5478-iman-dalam-pandangan-ahlus-sunnah-waljamaah.html. diakses pada 30 Mei 2019. 